\title{
ASSESSMENT, MONITORING AND EARLY WARNING SYSTEM FOR DESERTIFICATION BASED ON WATER CRITERION (CASE TUDY: KASHAN, IRAN)
}

\author{
H. Khosravi ${ }^{1}$, GH.R. Zehtabian ${ }^{1}$, A. Abolhasani ${ }^{1}$, H. Eskandari Damaneh ${ }^{1}$ \\ ${ }^{1}$ Department of Reclamation of Arid and Mountains Regions, Faculty of Natural Resources, University of Tehran, Iran - \\ (hakhosravi,ghzehtab, hamed.eskandari)@ut.ac.ir, azamabolhasani67@yahoo.com
}

KEY WORDS: Water, Criterion, Index, EC, IMDPA Model.

\begin{abstract}
:
Desertification is the third most important global challenge after crisis of water shortage and drought in the 21 st century. Many countries, especially developing countries, are faced this phenomenon. Identifying the regions exposed to this phenomenon is so important for combating desertification. Regarding to the importance of this phenomenon, in this study, we assessed desertification in Kashan, Iran, using IMDPA model and GIS software. According to the region condition, water was selected as the criterion and some indices were identified for it. For monitoring, the effect of criterion and indices changes was investigated during 1966-1974, 1974-1992, 1992-2002 and 2002-2011. Finally, for providing the desertification early warning system, data related to the criterion and indices were collected during 2003-2011 and the threshold of each index was determined. The results showed that the class of desertification based on Electrical Conductivity index was very severe in the study area, so this index is one of the most important desertification indices in arid areas in Iran.
\end{abstract}

\section{INTRODUCTION}

Desertification is defined as land degradation in arid, semi-arid and dry sub-humid regions because of natural factors or anthropogenic factors. Desertification is accounted as the third most important global challenge after crisis of water shortage and drought in the $21^{\text {st }}$ century. More than $80 \%$ of Iran has arid, semi- arid and dry sub-humid condition which is exposed to desertification. By identifying the criteria and indices of different regions and monitoring of them, it is possible to evaluate main factors of desertification and offer desertification early warning system.

Nowadays, early warning system is a key factor for reducing the negative impacts of desertification. This system is based on monitoring the desertification criteria and indices and comparing the results of monitoring with the threshold of each index. The main purpose of this system is awareness of the risk and decision making to reduce the negative effects. A complete and effective early warning system consists of risk recognition, monitoring and warning services, publications and communications and responsiveness.

As regards there is no system for monitoring the changes of criteria and indices in Iran, this research can be effective for controlling desertification and reducing the effects of it.

Many studies have been done for assessing land degradation and desertification intensity:

(Seif and El-Khashab, 2018) assessed desertification risk of sand dunes in Middle Egypt. (Azad et al, 2017) assessed desertification using water criterion in Iran Central arid regions and concluded that TDS index played a main role in the desertification of Biabanak region. (Kosmas et al, 2014) evaluated indicators for land degradation and desertification monitoring and concluded that among the most important indicators identified as affecting land degradation and desertification risk were rain seasonality, slope gradient, plant cover, rate of land abandonment, land-use intensity, and the level of policy implementation. (Akbari et al, 2016) assessed the hazard and risk of desertification in the semi-arid western regions of Golestan Province in Iran and concluded that the intensity of desertification was estimated to be medium and among the factors affecting desertification, agriculture by the weighted average of 3.22 had the highest effect. (Harahsheh et al, 1998) prepared desertification map of west Asia using GIS and RS. (Zolfaghari and Khosravi, 2016) assessed desertification severity of Saravan in Iran using IMDPA model. (Niko, 2011) assessed desertification potential for identifying effective factors on land degradation in Damghan region, Iran.

Regarding to these studies, recognition of criteria and indicators of desertification and determining the most important factors affecting desertification is necessary to prevent the spread of this phenomenon. In this research, IMDPA model (Iranian Model of Desertification Potential Assessment) was used for assessing, monitoring and providing desertification early warning system.

\section{METHODS AND MATERIALS}

\subsection{Study area}

The study area is located between $51^{\circ} 6^{\prime} 35^{\prime \prime}$ to $51^{\circ} 33^{\prime} 5^{\prime \prime}$ eastern longitude and $33^{\circ} 52^{\prime} 34^{\prime \prime}$ to $34^{\circ} 20^{\prime} 3^{\prime \prime}$ northern latitude, $240 \mathrm{Km}$ far from south of Tehran, on the margin of the desert in Esfahan province. The area of the region is about 93400 ha. The region is limited to Salt Lake from east and northeast, to mountains from west and to the south of Kashan County from south. This region has few water resources with low quality because of low rainfall and extreme evaporation due to high temperature and strong winds. 


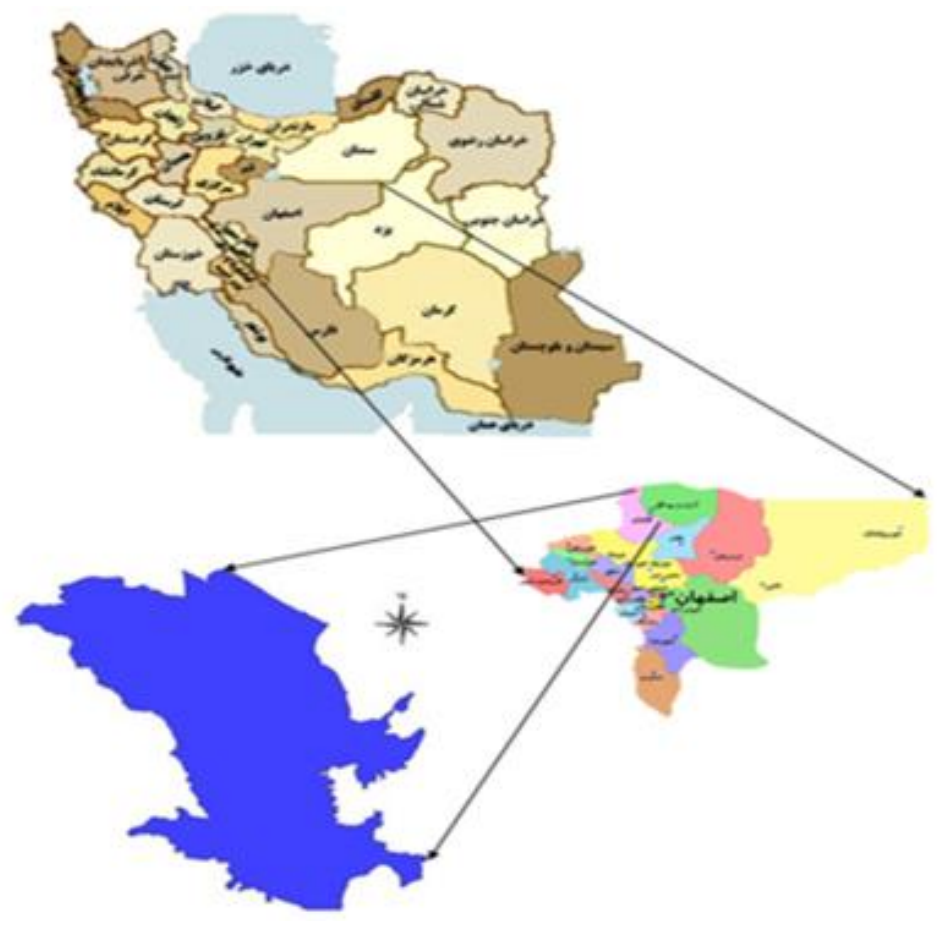

Figure 1. Location of the study area in Iran and Esfahan province

\subsection{Methodology}

In this research, IMDPA model was used for assessing the status of desertification in the study area. This model provides acceptable results for Iran because of using geometric mean of data. Water was selected as the criterion in the region and some indices were determined for it. The indices were as below:

Water: groundwater drop, SAR, EC

Each index received a weight (1 to 4 ) according to the expert opinion and water criterion was obtained based on its indicators geometric mean according to the formula below:

Index $-X=[(\text { Layer }-1) .(\text { layer }-2) \ldots(\text { Layer }-n)]^{1 / n}$

Index X: each criterion

Layer: indicators related to each criterion
$\mathrm{N}$ : number of indicators related to each criterion

Finally, desertification map of the region based on water criterion was determined. This map can be used for assessing the effects of indicators on desertification.

In the monitoring section, trend and the effect of water criterion and its indicators changes were evaluated during 1966-1974, 1974-1992, 1992-2002 and 2002-2011. Finally, for providing the desertification early warning system, data related to the criterion and indices were collected during 2003-2011and the threshold of each index was determined.

\section{RESULTS}

Desertification class of water indicators is shown in figure 2 . Evaluating the average weight of indicators showed that Electrical Conductivity was the most effective index on desertification based on water criterion (table 1).

\begin{tabular}{|c|c|c|c|}
\hline Row & Indicators & Average weight & Class of desertification \\
\hline 1 & Groundwater drop & 2.54 & Severe \\
2 & EC & 2.9 & Sever \\
3 & SAR & 1.7 & Medium \\
\hline
\end{tabular}

Table 1. Average weight of indicators affecting desertification based on water criterion 

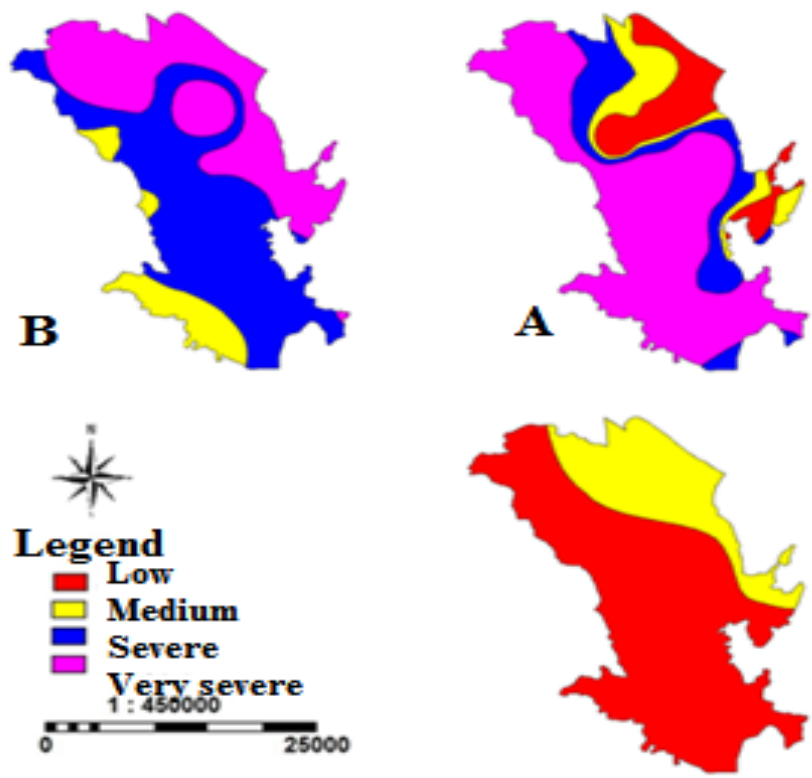

C

Figure 2. Desertification class of water indicators (A: groundwater drop, B: EC, C: SAR)

Figure 3 shows desertification map of the region based on water criterion. $75.07 \%$ (70012 ha) of the region is in medium class and $24.94 \%$ (23388 ha) is in severe class located on the north and east of the region.

\subsection{Groundwater drop index}

According to the results, the amount of groundwater drop in the center and south of the region was higher than north parts and reducing the groundwater quality has led to the fewer drop (figure 4).

According to the experts' opinion, the threshold of groundwater drop was $30 \mathrm{~cm}$ per year. Figure 5 shows the regions in the warning stage during 2003-2011.

The most extent under warning stage was related to 2008, 2007 and 2011 respectively so that $98.91 \%$ of the region was in warning stage in 2008 (table 2).

\subsection{EC index}

The class of EC index became more severe from the south to the north and from the west to the east. On the other hand, by approaching the Salt Lake, the quality of water became worse (figure 6).
According to the Schoeller diagram, the threshold of EC was $3000 \mu \mathrm{mho} / \mathrm{cm}$. Figure 7 shows the regions in the warning stage based on EC during 2003-2011.

The most extent under warning stage was related to 2008, 2009 and 2004 respectively so that 73970,73250 and 72407 ha of the region was in warning stage (table 3 ).

\subsection{SAR index}

According to the results, the amount of SAR had no significant changes during 2003-2011 and was in low class in the most of the region, except 2004 which was in medium class. Figure 8 shows the map of desertification class based on SAR during 2003-2011.

According to the experts' opinion, the threshold of SAR was 16 $\mu \mathrm{mho} / \mathrm{cm}$ per year. Figure 9 shows the regions in the warning stage during 2003-2011.

The extent of areas under warning stage based on SAR index is shown in table 4. 


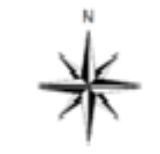

\section{Legend}
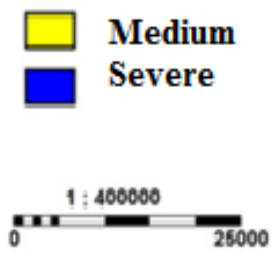

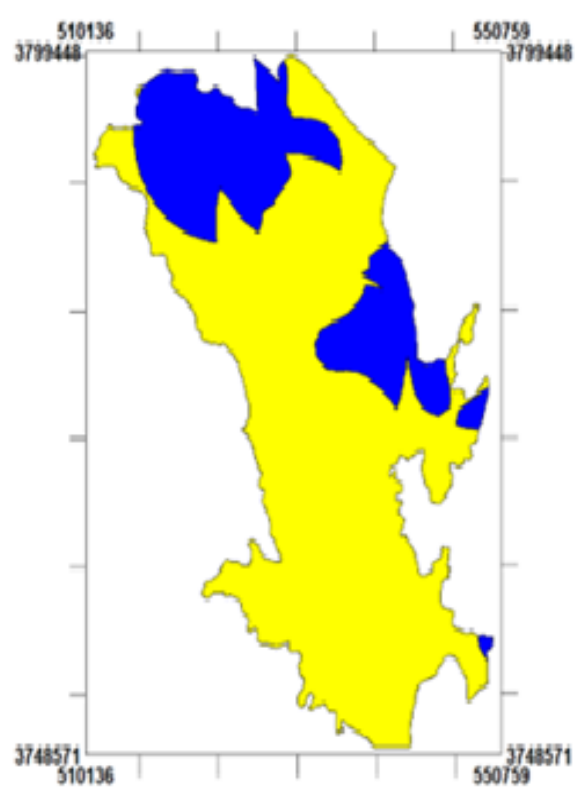

Figure 3. The map of desertification status based on water criterion

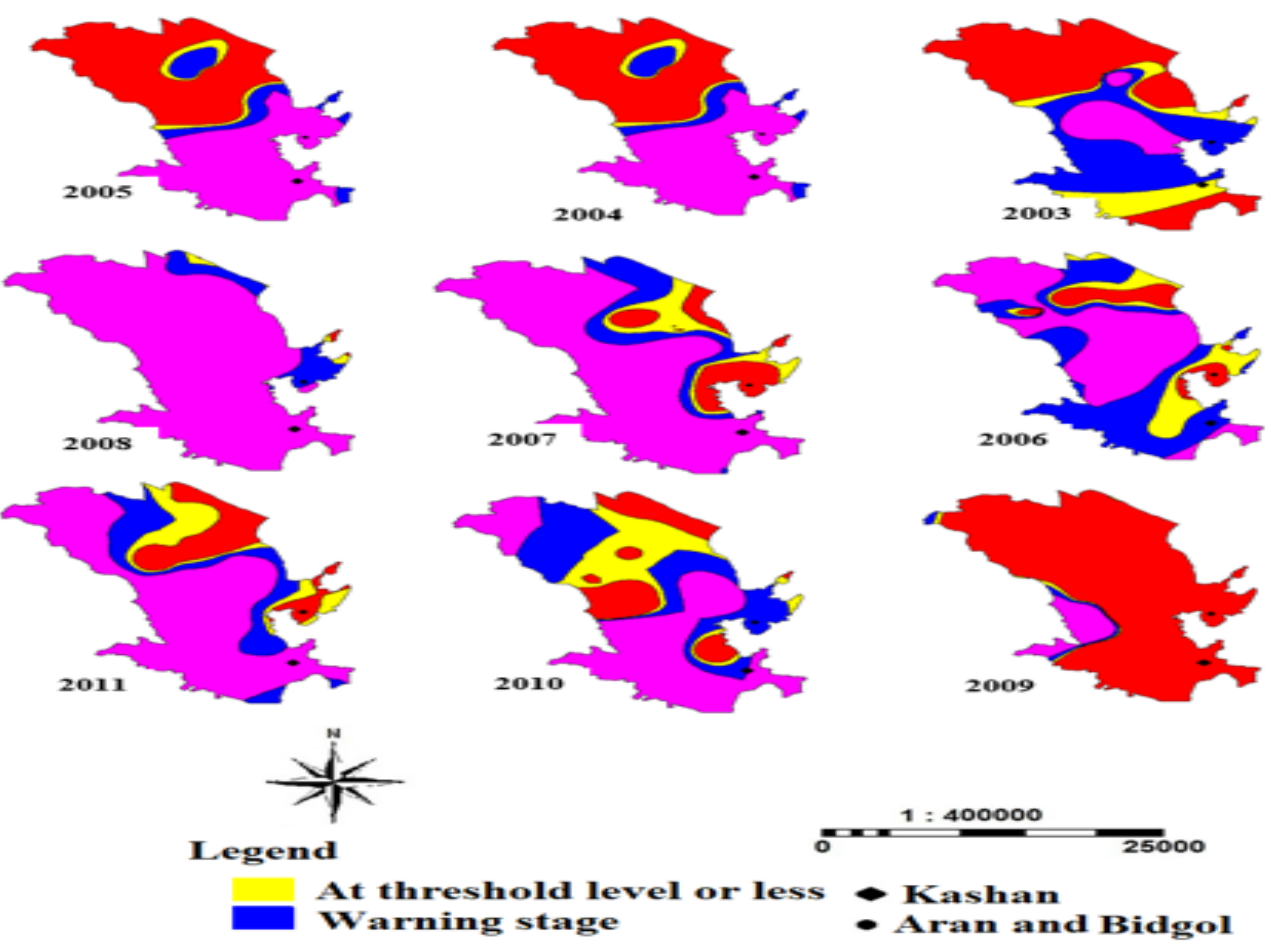

Figure 4. Map of desertification class based on groundwater drop during 2003-2011 


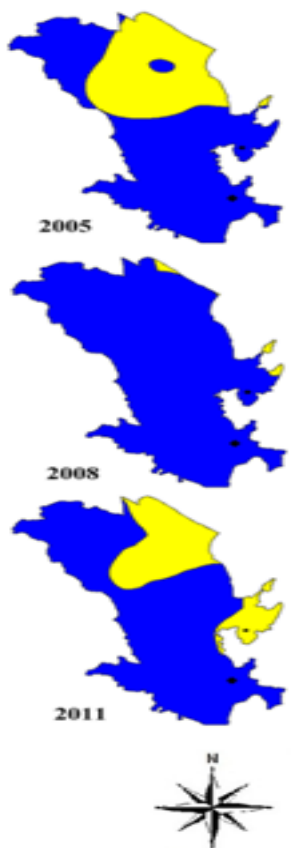

Legend
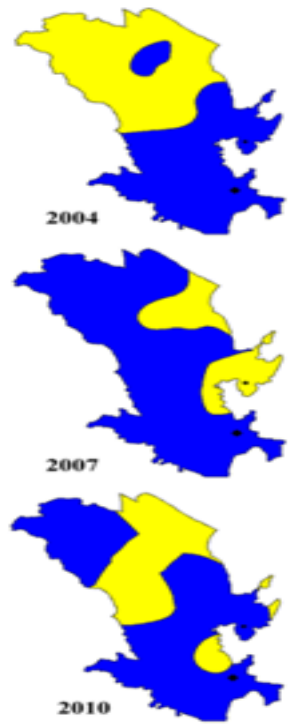

2010
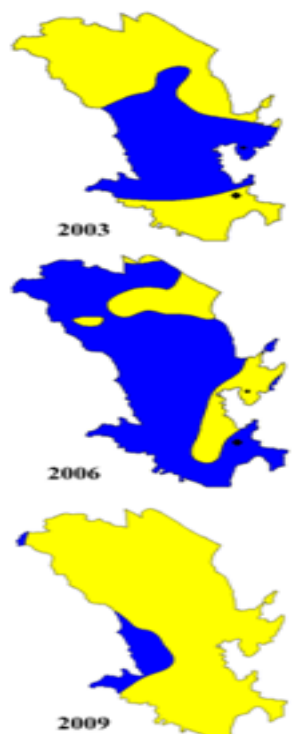

$1: 400000$

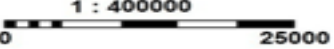

At threshold level or less - Kashan

Warning stage

Figure 5. The areas under warning stage based on groundwater drop (2003-2011)

\begin{tabular}{|c|c|c|c|c|}
\hline Year & \multicolumn{2}{|c|}{ At threshold level or less } & \multicolumn{2}{|c|}{ Warning stage } \\
\cline { 2 - 5 } area & ha & $\%$ & ha & $\%$ \\
\hline 2003 & 53376 & 57.40 & 40024 & 42.60 \\
2004 & 46001 & 48.96 & 47399 & 51.04 \\
2005 & 30940 & 32.93 & 62460 & 67.07 \\
2006 & 20331 & 21.64 & 73069 & 78.36 \\
2007 & 17969 & 19.13 & 75431 & 80.87 \\
2008 & 1025 & 1.09 & 92375 & 98.91 \\
2009 & 85958 & 92.08 & 7442 & 7.92 \\
2010 & 30008 & 31.94 & 63392 & 68.06 \\
2011 & 23522 & 25.04 & 69878 & 74.96 \\
\hline
\end{tabular}

Table 2. The extent of areas under warning based on groundwater drop during 2003-2011 


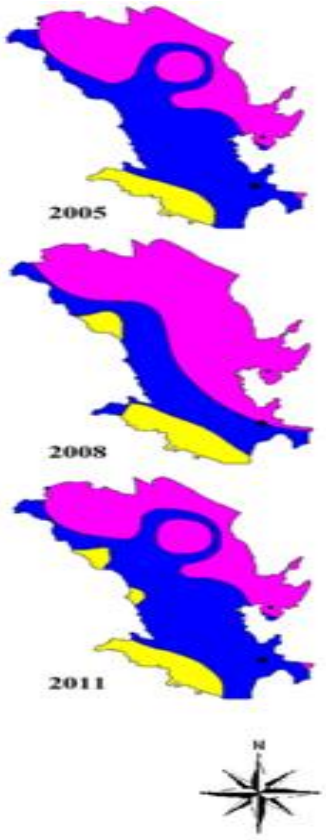

Legend

At threshold level or less - Kashan

Warning stage

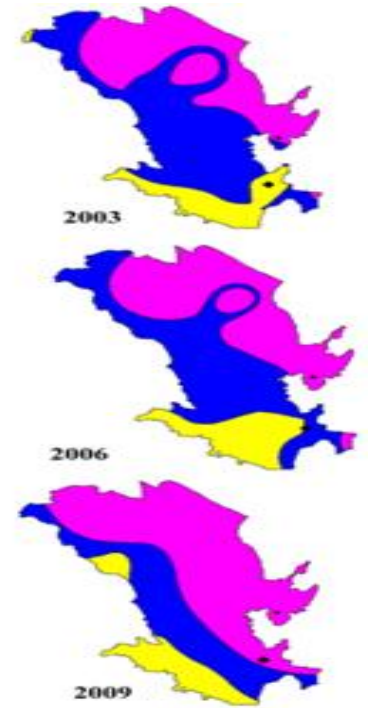

2009

Figure 6. Map of desertification class based on EC during 2003-2011
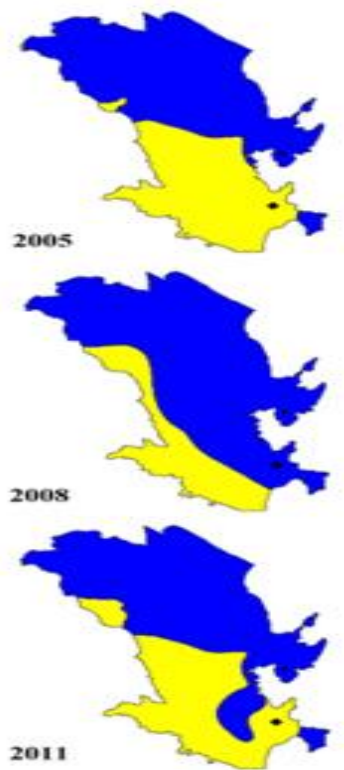

गर

Legend
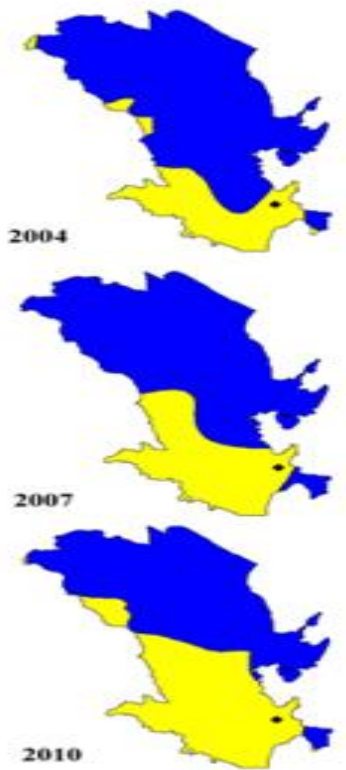

2010

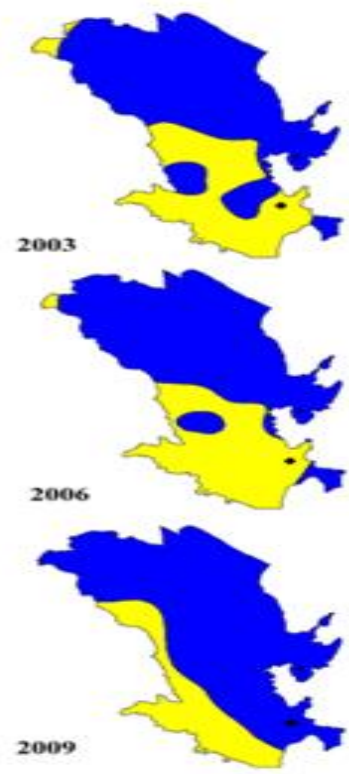

$1=400000$

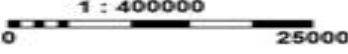

At threshold level or less - Kashan

Warning stage

- Aran and Bidgol

Figure 7. The areas under warning stage based on EC (2003-2011) 


\begin{tabular}{|c|c|c|c|c|}
\hline Year & \multicolumn{2}{|c|}{ At threshold level or less } & \multicolumn{2}{|c|}{ Warning stage } \\
\cline { 2 - 5 } area & ha & $\%$ & ha & $\%$ \\
\hline 2003 & 30453 & 32.42 & 62947 & 67.59 \\
2004 & 20993 & 22.35 & 72407 & 77.65 \\
2005 & 36185 & 38.52 & 57215 & 61.48 \\
2006 & 31640 & 33.68 & 61760 & 66.32 \\
2007 & 27516 & 29.29 & 65884 & 70.71 \\
2008 & 20141 & 21.44 & 73259 & 78.56 \\
2009 & 19430 & 20.68 & 73970 & 79.32 \\
2010 & 38541 & 41.02 & 54859 & 58.98 \\
2011 & 33458 & 35.61 & 59942 & 64.39 \\
\hline
\end{tabular}

Table 3. The extent of areas under warning based on EC during 2003-2011

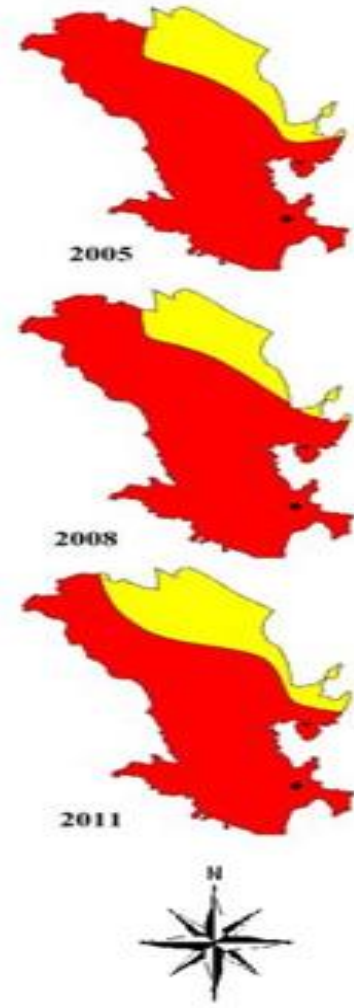

Legend
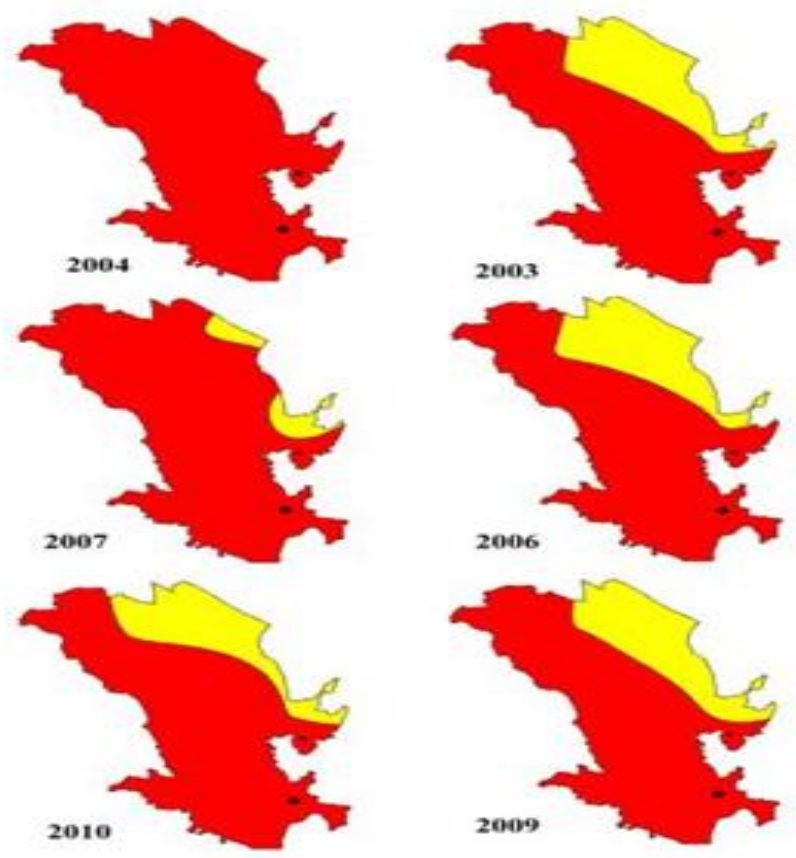

$1: 400000$

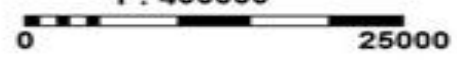

\section{At threshold level or less Warning stage \\ Kashan \\ - Aran and Bidgol}

Figure 8. Map of desertification class based on SAR during 2003-2011 


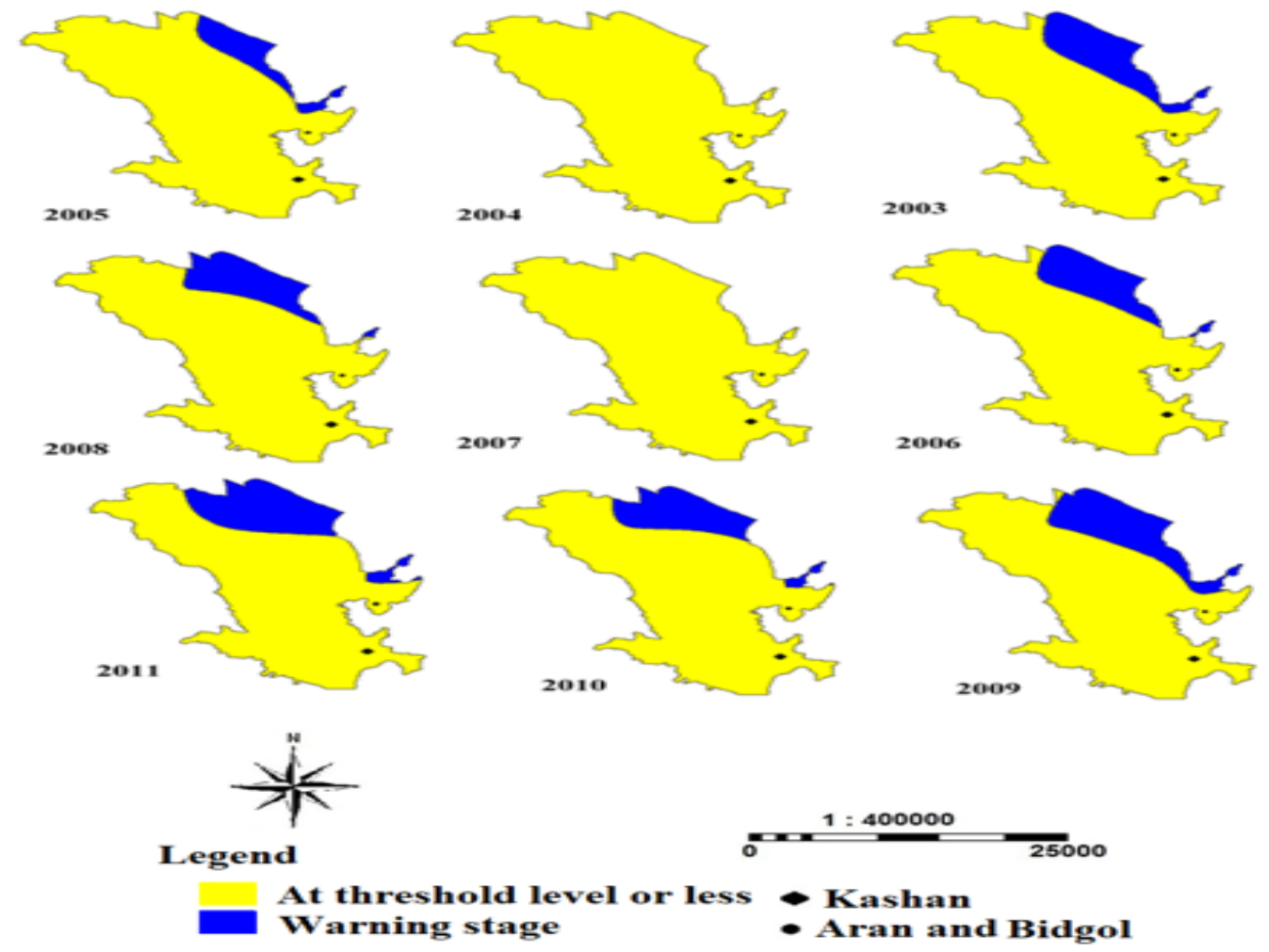

Figure 9. The areas under warning stage based on SAR (2003-2011)

\begin{tabular}{|c|c|c|c|c|}
\hline \multirow{2}{*}{ Year } & \multicolumn{2}{|c|}{ At threshold level or less } & \multicolumn{2}{c|}{ Warning stage } \\
\cline { 2 - 5 } & ha & $\%$ & ha & $\%$ \\
\hline 2003 & 79636 & 85.35 & 13764 & 14.65 \\
\hline 2004 & 93400 & 100 & - & - \\
\hline 2005 & 85910 & 92.03 & 7490 & 7.97 \\
\hline 2006 & 92209 & 87.32 & 1191 & 12.68 \\
\hline 2007 & 93400 & 100 & - & - \\
\hline 2008 & 92216 & 87.40 & 1184 & 12.60 \\
\hline 2009 & 78165 & 83.20 & 1578 & 16.80 \\
\hline 2010 & 80430 & 86.20 & 12970 & 13.80 \\
\hline 2011 & 76528 & 82.04 & 16872 & 17.96 \\
\hline
\end{tabular}

Table 4. The extent of areas under warning based on SAR during 2003-2011

\section{CONCLUSION}

The results of this study showed that the desertification status based on EC index was very severe in the region. This result was consistent with (Shakerian et al, 2012), (Khosravi et al, 2011) and (Dolatshahi, 2008). This similarity is due to the similar causes including salinity of water resources, water table depletion, high evaporation and groundwater overuse. Generally, the results showed that EC is an important factor affecting desertification in arid areas in Iran.

\section{REFERENCES}

Akbari, M., Ownegh, M., Asgari, H.R., Sadoddin, A., Khosravi, H., 2016. Desertification risk assessment and management program, Global Journal of Environmental Science and Management, 2(4), 365-380.
Azad, B., Fatahi, A., Ara, H., 2017. Desertification Assessment by Using Water Criterion in Iran's Central Arid Regions, Journal of Applied Environmental and Biological Sciences, 7(1), 188-197.

Dolatshahi, R., 2007. Preparing the map of desertification using IMDPA model based on water, soil and vegetation criteria (Case study: south of Garmsar, Iran), thesis for Msc degree, faculty of natural resources, university of Tehran.

Harahsheh, H., Tateishi, R., 1998. Desertification Mapping of West Asia_a GIS and Remote Sensing Application. Center for Environment Remote Sensing, Chiba University, Japan.

Khosravi, H., Zehtabian, Gh., Ahmadi, H., Azarnivand, H., 2011. Using IMDPA Model for Mapping Groundwater 
Degradation in Iran, GeoInformation for isaster Management, 38 May, Antalya, Turkey.

Kosmas, C., Kairis, O., Karavitis, C., Ritsema, C., Salvati, L., Acikalin, S., Alcalá, M., Alfama, P., Atlhopheng, J., Barrera, J., Belgacem, A., 2014. Evaluation and selection of indicators for land degradation and desertification monitoring: methodological approach, Environmental management, 54(5), 951-970.

Niko, sh., 2011. Assessing desertification potential based on IMDPA model in order to determine effective factors on land degradation (Case study: Damghan region), thesis for $\mathrm{PhD}$ degree, faculty of natural resources, university of Tehran.

Seif, E.S.S.A., El-Khashab, M.H., 2018. Desertification Risk Assessment of Sand Dunes in Middle Egypt: A Geotechnical Environmental Study. Arabian Journal for Science and Engineering, 1-19.

Zolfaghari, F., Khosravi, H., 2016. Assessment of desertification intensity of Saravan region using IMDPA model, Journal of Geography and Environmental Planning (GEP), 27(2), 87-102. 